\title{
A Longitudinal Study of Students' Perceptions of Using Deep Breathing Meditation to Reduce Testing Stresses
}

\author{
Gina Paul \\ Medical/Dental Preparatory Program \\ Southern Illinois University School of Medicine \\ Carbondale, Illinois, USA \\ Barb Elam \\ Wellness Center \\ Southern Illinois University Carbondale \\ Carbondale, Illinois, USA \\ Steven J. Verhulst \\ Statistics and Research Consulting \\ Southern Illinois University School of Medicine \\ Springfield, Illinois, USA
}

\begin{abstract}
Background: Stress can impact student performance. Yet few medical schools provide students with a consistent opportunity to develop and regularly practice stressreduction techniques to aid them academically.

Description: A curriculum component designed to assist 64 postbaccalaureate minority students in developing and practicing a stress-management technique was implemented on a regular basis from June 2004 to April 2006. Students participated in Deep Breathing Meditation exercises in two classes and completed pre-, post-, and follow-up surveys each academic year.

Evaluation: Students reported having perceptions of decreased test anxiety, nervousness, self-doubt, and concentration loss, using the technique outside of the two classes, and believing it helped them academically and would help them as a physician.

Conclusions: The Deep Breathing Meditation technique was successfully implemented each academic year, and it provided students with a promising solution for meeting challenging academic and professional situations.
\end{abstract}

It is widely accepted that medical school can be stressful. $^{1-9}$ Since the late 1980 s a growing number of medical schools and universities have offered students stress-reduction programs. ${ }^{10-14}$ More recently, schools such as Georgetown University, University of Maryland School of Medicine, Stanford University, and University of Massachusetts Medical School have incorporated or introduced the use of mind-body exercises into the curriculum to help students develop stress-reduction techniques. ${ }^{10,12}$ Although there is an individual optimal stress level that can enhance one's performance, too much stress or test anxiety can also hinder an individuals performance. ${ }^{15-17}$ Studies have revealed that being a student, not just a medical student, is stressful ${ }^{2,3}$ and that students' main concerns are academic performance and/or test anxiety. $2,5,6,12,14,18-21$

Test anxiety, a type of distress, has a physiological component. Research studies have found that elevations in corticosteroid levels (hormones released during times of distress) can impair declarative memory, concentration, and learning. ${ }^{22-26}$ Thus, high levels of stress can make it more difficult for students to concentrate and comprehend information. ${ }^{15}$ Consequently, students may have the cognitive ability yet perform poorly in testing situations due to stress or a resulting test anxiety interfering with their concentration and ability to process information. ${ }^{27}$ In addition, there is a psychological component to test anxiety. ${ }^{27,28}$

We thank Mr. Thomas Shea for the collection of data and Mr. Jerry Passon for his editing skills.

Correspondence may be sent to Gina Paul, Academic Enrichment, School of Medicine, Wheeler Hall, Mailcode 4323, Carbondale, IL 62901-4323, USA. E-mail: rpaul@siumed.edu 
The worry or emotional arousal that can accompany test anxiety causes the student to become centered on the "self" during an exam rather than the task, thus possibly negatively influencing future academic performance if no coping techniques are adopted.

According to Harris and Coy, ${ }^{18}$ students should use diaphragmatic breathing during exams in attempts to calm or center themselves. Results from research studies that examined students who meditated or used diaphragmatic breathing showed significant increases in students' academic learning and achievement. ${ }^{11,13,17,29}$ Diaphragmatic breathing is known to counteract the fight or flight response symptoms that are often associated with anxiety. ${ }^{15,30}$ When a student perceives the exam to be a challenge or has low self-confidence from previous testing experiences, he or she may experience the physiological symptoms previously discussed in addition to the symptoms associated with the fight or flight response that include increased heartbeat, respiration, blood pressure, muscle tension, and gastric discomfort.Meditation can also be used to counteract stressful situations, as it is a technique to develop concentration and awareness to produce a calming effect; diaphragmatic breathing is central to any meditation practice. ${ }^{5,30,31}$

Many in academic medicine have called for medical schools to help students learn effective coping strategies to alleviate the academic stresses associated with negative performance. ${ }^{7,12,32-34}$ Therefore, Southern Illinois University School of Medicine's Medical/Dental Preparatory Program (MEDPREP) has initiated a curriculum component to help students develop a coping technique to manage their perceived academic stresses and/or test anxiety.

The purpose of this article is to describe a 10-month longitudinal study conducted over a 2-year period to assess the MEDPREP students' perceived symptoms and beliefs regarding the stresses associated with testing situations and academics. In addition, we examined the changes in their use of Deep Breathing Meditation (DBM) as a tool to counter the symptoms associated with testing stresses.

\section{Methods}

\section{Participants}

Sixty-four postbaccalaureate premedical students enrolled in MEDPREP at Southern Illinois University School of Medicine during the academic years of 2004-05 (Group 1) and 2005-06 (Group 2) participated in the study; 32 students participated in each academic year for a total of 64 participants. The combined study groups comprised 53 women and 11 men. Of these participants, there were 58 Black, 4 Hispanic, 1 Asian, and 1 Native American. Seventy- seven percent of the students had taken the Medical College Admission Test (MCAT) prior to enrollment.

\section{MEDPREP}

MEDPREP is a 2-year postbaccalaureate program designed to assist students underrepresented in medicine to prepare for the MCAT during the 1st year and in the 2nd year build a strong science foundation to prepare them for medical school matriculation. All of the students begin their 1st academic year in June as a cohort. During their 1st academic year, students take MEDPREP courses and usually one campus course (i.e., physiology, anatomy, genetics). MEDPREP courses include Biology, Chemistry, Physics, Career and Professional Development, Verbal Reasoning (VR), and Academic Enrichment (AE). The latter four courses have only one section during the summer. The VR course meets during the summer, fall (two sections), and spring semesters of the students' 1st year and addresses the skill development for the Verbal Reasoning and Writing Sample sections of the MCAT. The AE course has one section in the summer and fall; students develop such skills as stress management, time management, and study/test-taking skills.

\section{Study Design}

Because the students are enrolled in the same AE and VR classes during the summer, we were unable to have a control group. Thus, this is a descriptive study of MEDPREP students' perceptions regarding the presence or absence of academic stresses and their use of DBM.

During each 10-month study period, the two groups were surveyed at three different times using an instrument developed by the authors. The DBM Pretest was administered immediately prior to each group's first MEDPREP course of the summer semester, at the conclusion of the summer semester 6 weeks later (Posttest) and in April 2005 and 2006 after each group had taken the MCAT (Follow-up); this covered the period of June 29, 2004, through April 19, 2005, for Group 1, and June 28, 2005, through April 13, 2006, for Group 2.

The DBM instrument comprised questions with forced-choice options using a 10-point Likert-type scale from 1 (never) to 10 (all the time) to track any changes in students' perceived feelings and beliefs. All three surveys consisted of a definition of DBM as "several minutes of quiet time to focus on your breathing as a stress management strategy," four items to assess feelings of negative test anxiety and associated symptoms, two items regarding their current use of DBM, and one item to determine their belief of using daily DBM to help them academically. The Posttest survey also included a belief question regarding the 
use of DBM as helpful in medical school. The Followup survey consisted of the aforementioned items, two additional belief questions regarding future use, and one item to identify all of the situations in which students utilized DBM since matriculating into MEDPREP through their MCAT test-taking experience.

DBM is based on Benson's Relaxation Response. ${ }^{31} \mathrm{His}$ technique has four basic components: working in a quiet environment, using a mental device such as concentrated breathing to direct one's attention, being in a comfortable position where most of the body weight is supported, and having a receptive attitude. ${ }^{31}$ The first MEDPREP class that all of the students attended (AE) presented information concerning stress and test performance to create the awareness that this is an experience shared by students ${ }^{5}$ and, as recommended by Benson, ${ }^{31}$ to create a receptive attitude for using DBM as part of our course component. Students were also taught how to perform diaphragmatic breathing through a script written and conducted by one of the authors who is a licensed counselor specializing in stress management at the university. This script incorporates the remaining components of Benson's Relaxation Response previously listed (see Appendix). At the start of the second AE summer class, students performed approximately $5 \mathrm{~min}$ of $\mathrm{DBM}$; this was followed by a 1-hr lecture regarding the physiological effects of stress on learning and the body and results of experimental studies that utilized meditation to improve academic scores.

To verify that students were able to fully elicit the diaphragmatic breathing central to DBM, each student was evaluated during a private, 10-min session with the counselor using the HeartMath ${ }^{\mathrm{R}}$ Stress Management System produced by the Institute of HeartMath in Boulder Creek, California. ${ }^{32}$ The HeartMath device analyzes the heart rate and rhythm as a measure that reflects either a shallow breath from the chest or deep diaphragmatic breathing. All of the students were able to elicit the diaphragmatic breath reflective of neustress and Benson's Relaxation Response. ${ }^{31}$

The DBM curriculum component was primarily designed to assist students in decreasing any perceived feelings of negative academic performance, nervousness, or anxiety symptoms and aid them in developing a stress management technique they could use whenever they perceived themselves to have feelings of distress (i.e., nervousness, loss of concentration, self-doubt). The AE and VR semester courses began with approximately $5 \mathrm{~min}$ of DBM each time the classes met; students participated in DBM 30 times during each summer semester, 43 times during each fall semester, and 22 times during each spring semester for a total of 95 DBM sessions over each academic year. The data analyses of the three surveys were completed using the Statistical Analysis System to determine frequencies, means, standard deviations, and paired, two-tailed $t$ tests between surveys.

\section{Results}

The analysis of the Pretest to Follow-up data pertaining to the question regarding students practice of DBM before entering MEDPREP (data not shown) revealed that $67 \%(n=43)$ of the students responded they had never engaged in DBM prior to being introduced to it in class; $22 \%(n=14)$ had practiced DBM only as needed, and $11 \%(n=7)$ performed DBM an average of 2 days per week. At the end of each study period 10 months later, $100 \%$ of the students reported using DBM at least once in a situation (MCAT) not associated with the AE or VR classes where it was regularly practiced, $58 \%(n=37)$ used it only as needed, and $42 \%(n=27)$ practiced DBM an average of 4 days per week on their own.

The changes in mean scores in the six areas assessed for each survey over the 10-month study period are illustrated in Table 1. The greatest changes occurred within the first 6 weeks during the summer semesters. All six areas changed significantly during that time period; the students perceived significantly less test anxiety, nervousness, and self-doubt, in addition to increased concentration during exams. Although there was a significant decrease in students' perceived feelings of self-doubt during exams in the first 6 weeks, the greatest decrease occurred from the time between the Posttest to Follow-up. The students also began using DBM during exams in courses other than AE and VR and believed using DBM would help them academically.

The various situations in which the students engaged in DBM are illustrated in Table 2; the data were derived from the April Follow-up surveys only to determine if students utilized DBM outside of the AE and VR courses. The majority of them used it prior to initiating their practice verbal reasoning passages in and outside of VR, prior to and during the MCAT exam, and during exams in classes other than AE and VR. Almost half of the students reported engaging in DBM before quizzes in classes other than AE and VR. During the second year (2005-06), we also asked Group 2 $(N=32)$ if they used DBM when starting to lose concentration during exams other than AE and VR; 69\% $(n=22)$ responded they used DBM to counteract that mental state. Another $38 \%(n=12)$ responded that they used DBM before studying when alone.

In the Follow-up surveys only in both years, we asked the students to use the scale of 1 (not at all) to 10 (completely) to tell us about their beliefs regarding their use of DBM in the future and to what extent they became engaged in the DBM component during the AE and VR classes. The students reported they 
PAUL, ELAM, \& VERHULST

Table 1. Change in Students' Perceptions and Use of DBM Over Time

\begin{tabular}{|c|c|c|c|c|c|c|}
\hline Survey Questions & $\begin{array}{l}\text { Pretest M (SD): } \\
\text { June }\end{array}$ & $\begin{array}{c}\text { Posttest M (SD): } \\
\text { August }\end{array}$ & $\begin{array}{c}\text { FU M (SD): } \\
\text { April }\end{array}$ & d (Pre, Post) & d (Post, FU) & d (Pre, FU) \\
\hline \multicolumn{7}{|c|}{ To what extent do you currently } \\
\hline $\begin{array}{l}\text { Experience test anxiety (rapid } \\
\text { heartbeat, butterflies, headache, } \\
\text { worry about failing) }\end{array}$ & $6.3(2.25)$ & $4.92(2.09)$ & $3.97(2.27)$ & $-0.61^{*}$ & $-0.45^{*}$ & $-1.04 *$ \\
\hline Become nervous during exams & $5.98(2.31)$ & $4.67(2.0)$ & $3.83(2.22)$ & $-0.57 *$ & $-0.42 *$ & $-0.93 *$ \\
\hline Have self-doubt during exams & $6.16(2.29)$ & $5.19(2.32)$ & $4.16(2.23)$ & $-0.42 *$ & $-0.44 *$ & $-0.87 *$ \\
\hline Lose concentration during exams & $5.95(2.3)$ & $3.98(2.04)$ & $4.02(2.06)$ & $-0.86^{*}$ & 0.02 & $-0.84 *$ \\
\hline $\begin{array}{l}\text { Use DBM if you become } \\
\text { anxious/upset during an exam }\end{array}$ & $2.5(2.13)$ & $6.03(2.57)$ & $6.92(2.16)$ & $1.66^{*}$ & $0.35^{*}$ & $2.08 *$ \\
\hline $\begin{array}{l}\text { Believe that using DBM on a daily } \\
\text { basis can help you improve } \\
\text { academically }\end{array}$ & $6.25(2.63)$ & $8.16(1.99)$ & $7.85(2.13)$ & $0.73^{*}$ & 0.16 & $0.61^{*}$ \\
\hline
\end{tabular}

Note. $N \approx 64 . \mathrm{DBM}=$ Deep Breathing Meditation; $\mathrm{FU}=$ Follow-up; $\mathrm{d}=($ mean2 - mean 1$) /$ standard deviation of the pretest; $\mathrm{d}=(\mathrm{mean} 3-$ mean2) / standard deviation of the pretest; $\mathrm{d}=$ (mean 3 - mean 1$)$ / standard deviation of the pretest.

${ }^{*} p<.05$ with paired $t$-test.

believed using DBM would be helpful in medical school $(M=8.28, S D=1.89)$ and as a physician $(M=8.27, S D=1.89)$; they also anticipated using it in the future $(M=7.83, S D=2.71)$. Overall, students reported becoming very engaged in the DBM segment during the VR and AE classes $(M=8.17, S D=1.94)$.

\section{Conclusion}

This research study was based on the premise that it is not enough to lecture students about stress management strategies during orientation or as an isolated unit. Rather, students must be provided with regular opportunities to develop and practice a strategy as it takes time to abandon an ineffective behavior and replace it with a behavior that is empowering. Our findings suggest that significant behavior changes occurred when MEDPREP students were given a continuous opportunity to practice a 5-min stress reduction tech-

Table 2. Students Use of DBM (April 2005 and 2006 Follow-up Only)

\begin{tabular}{|c|c|c|}
\hline Student Usage of DBM (Check All That Apply) & $n$ & $\%$ \\
\hline Before the MCAT started ${ }^{a}$ & 57 & 95 \\
\hline Before class practice VR passages & 60 & 95 \\
\hline Before exams in classes other than $\mathrm{AE}$ and VR & 52 & 81 \\
\hline Before doing practice VR passages not in VR class & 48 & 75 \\
\hline At the start of each MCAT section ${ }^{a}$ & 40 & 67 \\
\hline During the MCAT sections ${ }^{a}$ & 39 & 65 \\
\hline Before quizzes in classes other than $\mathrm{AE}$ and VR & 31 & 48 \\
\hline As a start to a study group & 10 & 16 \\
\hline
\end{tabular}

Note. $N \approx 64$. DBM $=$ Deep Breathing Meditation; MCAT $=$ Medical College Admission Test; VR = Verbal Reasoning; AE $=$ Academic Enrichment.

${ }^{a} N=60$ students took the MCAT in April 2005 and 2006. nique meant to reduce the physiological and psychological effects that can be associated with academic stress.

To our knowledge, only a limited number of medical schools provide opportunities to fully develop and use a stress reduction technique as a regular part of the curriculum for all students. ${ }^{11}$ However, it has been suggested in the literature that medical students be provided with educational interventions that teach them effective coping strategies as a proactive measure to counteract distress. ${ }^{5,7,12,32,33,36,37}$ The DBM course component allowed students, who might not acknowledge or understand the consequences of stress, to acquire and utilize a coping mechanism to call on as stressful situations occurred and triggered the fight or flight response, a common human phenomenon. ${ }^{15}$

We believed that the successful implementation of the DBM component necessitated a full explanation of the science supporting the inclusion of this component so that students would be receptive and engage in the DBM sessions. From student comments, using the HeartMath monitor to evaluate their ability to elicit diaphragmatic breathing helped to verify whether they were breathing deep enough. Overall, it appeared that the students became engaged in the DBM component. In March 2005, 9 months into the 1st year of the study, a student apologized for not engaging in the DBM component and for always silently questioning why we had this as part of the class; however, the student now understood why it was helpful and came to thank us for including it in the curriculum. For some students, it may take longer to become receptive and participate in the DBM component. Thus, it is important to offer students the opportunity to learn a technique and allow for continued practice; we recommend that stress management components be integrated into the curriculum for all students. 
After 6 weeks, students perceived the positive effects of increasing concentration and decreasing test anxiety, nervousness, and self-doubt during exams. Although we did not analyze the presence of stress hormones in our participants, these findings are consistent with our knowledge of how increases in stress hormones can cause a range of cognitive $\mathrm{e}^{2,3,16-18}$ and physical $^{15}$ symptoms that our participants reported experiencing. Despite the group size, significant changes in all areas of concern were observed after exposure to DBM from the Pretest to the Follow-up.

In addition to the benefits discussed, there is no monetary cost involved with incorporating DBM into the curriculum, unless the institution chooses to purchase a HeartMath system. However, providing students with this opportunity also requires that the faculty be receptive to leading the students in the guided meditation at the start of lectures, tutor groups, and exams. As instructors, we sometimes rush to class; however, leading the DBM component allows one to also take a breath, clear the mind, and focus.

Our study has several limitations. The study results are based on students' self-reported perceptions and not on direct observations or measurements. Second, although these data provide evidence for an association between using DBM and students' perceptions of improved concentration and decreased anxiety, nervousness, and self-doubt, there are no data to demonstrate to what extent the summer and fall AE courses also contributed to these results. Last, this study was based on a small sample of postbaccalaureate premedical students underrepresented in medicine rather than a representative sample from the premedical student population; thus, we would be hesitant to generalize these results to the medical student population. Yet the results suggest that providing students with an opportunity to develop a stress management technique may have merit, particularly for students who experience some level of anxiety during evaluative sessions.

In conclusion, our goal was not necessarily to have the MEDPREP students engage in a daily practice of DBM but for them to recognize when they were experiencing distress and know how to react in a positive manner to counter their perceived symptoms. We believe the DBM intervention was successful based on the results indicating that (a) $100 \%$ of the students reported practicing DBM at some point prior to or during the MCAT, a stressful testing situation for many MEDPREP students; (b) the majority of students initiated DBM on their own prior to their exams outside of the AE and VR courses; and (c) almost half initiated DBM on their own before quizzes in classes other than $\mathrm{AE}$ and VR. Overall, it appears as though the students were able to develop a coping technique, used it in a variety of circumstances, and may continue to utilize DBM as they move forward into the demands of medical school and their lives as physicians.

\section{References}

1. Schuwirth L. Learning by scar formation. Medical Education 2004;38:769-99.

2. Aktekin M, Karaman T, Senol YY, et al. Anxiety, depression and stressful life events among medical students: A prospective study in Antalya, Turkey. Medical Education 2001;35:12-7.

3. Firth-Cozens J. Medical student stress. Medical Education 2001;35:6-7.

4. Toews JA, Lockyer JM, Dobson D, et al. Analysis of stress levels among medical students, residents, and graduate students at four Canadian Schools of Medicine. Academic Medicine 1997;72(11):997-1002.

5. Stewart SM, Betson C, Lam TH, et al. Predicting stress in first year medical students: A longitudinal study. Medical Education 1997;31:163-8.

6. Wolf TM, Heller, SS, Camp CJ, Faucett JM. The process of coping with a gross anatomy exam during the first year of medical school. British Journal of Medical Psychology 1995;68:85-7.

7. Mosley TH, Perrin SG, Neral SM, et al. Stress coping, and wellbeing among third-year medical students. Academic Medicine 1994;69:765-7.

8. Miller P McC. The first year at medical school: some findings and student perceptions. Medical Education 1994;28:5-7.

9. Deary J. Need medical education be stressful? Medical Education 1994;28:55-7.

10. Santana S. Mind-body treatments gain foothold in medical curriculum. AAMC Reporter 2005; January:8-9.

11. Horneffer K. Promoting student wellness in higher education: The use of relaxation breathing in the classroom. Wellness Management. Available at: http://www.nationalwellness.org/ index.php?id=237@id_tier=201. Accessed April 42003.

12. Lee J, Graham A. Students' perceptions of medical school stress and their evaluation of a wellness elective. Medical Education 2001;35:652-9.

13. Hall P. The effect of meditation on the academic performance of African-American college students. Journal of Black Studies 1999;29:408-15.

14. Wolf TM, Randall HM, Faucett JM. A survey of health promotion programs in the US and Canadian medical schools. American Journal of Health Promotion 1988;3:33-6.

15. Seaward B. Managing stress. Boston: Jones and Bartlett, 2002.

16. Hembree R. Correlates, causes, effects, and treatment of test anxiety. Review of Educational Research 1988;58:47-77.

17. Benson B, Wilcher M, Greenberg B, et al. Academic performance among middle school students after exposure to a relaxation response curriculum. The Journal of Research and Development in Education 2000;33:156-65.

18. Harris HL, Coy, DR. Helping students cope with test anxiety. ERIC Digest (ED479355) 2003. Available at: http://eric.ed.gov/ERICDocs/data/ericdocs2/content_storage _01/0000000b/80/2a/3a/0c.pdf. Accessed April 42003.

19. Stewart SM, Lam TH, Betson CM, et al. A prospective analysis of stress and academic performance in the first two years of medical school. Medical Education 1999;33:243-50.

20. Stecker T. Well-being in an academic environment. Medical Education 2004;38:465-78.

21. Gallagher TH, Munro J, Kahl LE. Development and implementation of a clerkship counseling hotline. Teaching and Learning in Medicine 2005;17;80-4.

22. Lupien SJ. Yearbook of science and technology. New York: McGraw Hill, 2003.

23. Lupien SJ. Biological psychiatry. Chichester, England: Wiley, 2002.

24. Lupien SJ, Brière S. Encyclopedia of stress, Volume 2. San Diego: Academic, 2000.

25. Lupien SJ, McEwen BS. The acute effects of corticosteriods on cognition: Integration of animal and 
human model studies. Brain Research Reviews 1997;24:127.

26. Kirschbaum C, Wolf OT, May M, Wippich W, Hellhammer DH. Stress-and treatment-induced elevations of cortisol levels associated with impaired declarative memory in healthy adults. Life Sciences 1996;58:1457-83.

27. Zeidner M. Does test anxiety bias scholastic aptitude test performance by gender and sociocultural group? Journal of Personality Assessment 1990;55:145-60.

28. Sarason IG, Sarason BR. Handbook of social and evaluation anxiety. New York: Plenum, 1990.

29. Matthews D, Quinn J. Relaxation training: A humanistic technique to increase achievement. Journal of Humanistic Education and Development 1987;25:112-21.

30. Mayo Clinic Special Report. Anxiety disorders: Taking control of persistent worries, fears, and phobias. Mayo Clinic Women's Healthsource 2005; July:1-8.

31. Benson B. The relaxation response. New York: HarperCollins, 2001.

32. Adams J. Straining to describe and tackle stress in medical students. Medical Education 2004;38:463-64.

33. Kiessling C, Schubert B, Scheffner D, Burger W. First year medical students' perceptions of stress and support: A comparison between reformed and traditional track curricula. Medical Education 2004;38:504-9.

34. Morrison J, Moffat, K. More on medical student stress. Medical Education 2001;35:617-8.

35. Institute of HeartMath. The inside story: Understanding the power of feelings. Boulder Creek, CA: Institute of HeartMath, 2002.

36. Moffat KJ, McConnachie A, Ross S, Morrison JM. Undergraduate medical education: First year medical student stress and coping in a problem-based learning medical curriculum. Medical Education 2004;38:482-91.

37. Wolf TM. Stress, coping and health: Enhancing well-being during medical school. Medical Education 1994;28:8-17.

38. Coombs RH, Virshup BB. Enhancing the psychological health of medical students: The student well-being committee. Medical Education 1994;28:47-54.

\section{Appendix}

\section{DBM Script Read at Every Class}

- Feet flat on the floor, hands comfortably in your lap or on the desk, sitting up straight—allow yourself to be supported by your chair .... and
- Let your eyes drift slowly closed, top lid . . touching the bottom lid, looking at the insides of your eyelids $\ldots \ldots$

- And let your body be still except for your breathing

- Going at your own pace . . notice your inhale ... . .... \& exhale . . . . . (time for $2+$ cycles after giving directive)

- With your next inhalation, pull your in-breath deep into your abdominal area ... like filling up a balloon with air.....

- Then .... exhale out ... out .... out ... until you can't exhale anymore (time for $2+$ cycles)

- Inhaling again, deep into your abdomen ... not holding on with your belly muscles - there's no need to hold on with your body ..... And on the exhalation, let your navel push back towards your spine on the exhale out .... out ..... out

- Deeply .... not forcing your breath, but not skimping on it either ... continue at your own pace (time for $2+$ cycles)

- Notice how on the inhale, the air is slightly cool past the tip of your nose ... And how on the exhale . . the air is now slightly warm past the tip of your nose ( $2+$ cycles)

- Notice how on the in-breath, your rib cage pulls apart ........ then collapses on the exhale (time for $2+$ cycles)

- With your next inhalation/exhalation cycles, try counting your breath ... so that

- If you inhale for $1 \ldots 2 \ldots 3 \ldots$, then exhale . . for 1...2. . 3. . .

- Your inhalations and exhalations might be shorter or longer, it doesn't matter . . . take the time now to try to match them (at least 5 complete cycles)

- Bringing yourself back to the room ... open your eyes ..... and take this calm feeling with you for the day.

Note. .... represents pauses in reading.

Final revision received November 272006 
Copyright of Teaching \& Learning in Medicine is the property of Lawrence Erlbaum Associates and its content may not be copied or emailed to multiple sites or posted to a listserv without the copyright holder's express written permission. However, users may print, download, or email articles for individual use. 